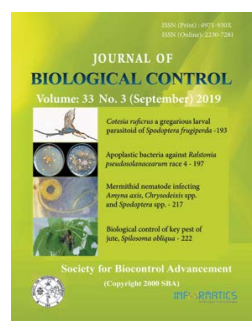

Research Note

\title{
Identification of larval salivary gland polytene chromosomes of the peach fruit fly, Bactrocera zonata (Saunders) (Diptera: Tephritidae)
}

\author{
FARZANA YESMIN ${ }^{*}$, M. NAZIM UDDIN ${ }^{2}$, G.M. SAIFUR RAHMAN ${ }^{3}$ and M. HASANUZZAMAN ${ }^{1}$ \\ ${ }^{1}$ Institute of Food and Radiation Biology, Atomic Energy Research Establishment, Bangladesh Atomic Energy Commission, \\ Ganakbari, Savar, GPO Box 3787, Dhaka 1000, Bangladesh \\ ${ }^{2}$ Directorate of Secondary and Higher Education, Dhaka, Bangladesh \\ ${ }^{3}$ Life and Earth Science Group, National University, Gazipur, Bangladesh \\ *Corresponding author E-mail: farzanayesmin75@yahoo.com
}

\begin{abstract}
Peach fruit fly, Bactrocera zonata (Saunders) (Diptera: Tephritidae) is native to South and South-East Asia. It is a polyphagous species and has a high reproductive potential (approx. 600 eggs in a lifetime), high biotic potential, i.e., several generations of progeny per year. The species has the rapid dispersal ability and can be active throughout the year. Its establishment may have a serious impact on the environment following the initiation of chemical and/or biological control programmes. B. zonata is of quarantine significance to EPPO (European and Mediterranean Plant Protection Organization) countries and it is classified on the A1 list of pests recommended for regulation as quarantine pests by Centre for Agriculture and Biosciences International (CABI). The present study initiates an attempt to identify the larval (3rd instar) salivary gland polytene chromosome arms of B. zonata using Olympus phase contrast microscope CX 41 . A photographic representation of the polytene chromosomes of this species associates with identifying tips as well as well defined characteristics of each polytene chromosome arms are described. Five long chromosomes with their identifying tips are recognized in each polytene nucleus. Polytene chromosomes are of special interest to construct a Genetic Sexing Strain (GSS) of a pest species and it can play an important role for the successful application of Sterile Insect Technique (SIT) in field application as part of the biological control programme under Integrated Pest Management (IPM) scheme.
\end{abstract}

KEY WORDS: Biological control, insect pest, peach fruit fly, polytene chromosomes

(Article chronicle: Received: 17-01-2019; Revised: 10-08-2019; Accepted: 01-09-2019)

The fruit flies are described under two families: Tephritidae and Lonchaeidae (Tephritoidea) and members of the Tephritidae family are known as "true fruit flies". It is the most species rich family containing over 5000 described species under 500 genera and many species are still to be described worldwide (Norrbom, 2010; Ucchoa and Nicacio, 2010). The flies are extremely polyphagous pests and infest a wide variety of economically important fruits and vegetables including peach, mango, pear, apple, guava, citrus, tomato, pepper, avocado, and cucurbits (Liu, 2013).

The genus Bactrocera (Macquart) comprehended 651 described species with approximately 70 polyphagous species attacking commercial fruits and vegetables. They are endemic to Southeast Asia and South Pacific islands (Drew, 2000) and subsist in subtropical or tropical rain forest. In Bangladesh at least 15 species under this genus have been confirmed (Leblanc et al., 2013). It creates a serious impediment for global trade (Clarke, 2011). Among them Bactrocera zonata (Saunders) is now distributed in more than 20 countries including India, Pakistan, Bangladesh, and Egypt. It is a significant fruit pest that causes severe damage to peach (Prunus persica), mango (Mangifera indica), guava (Psidium guajava) and many other fruits and vegetables (Qureshi et al., 1991; Kapoor, 1993). This species has wide dispersal ability and the adults can fly up to 40 $\mathrm{km}$ in search of new hosts (Qureshi et al., 1975). Its spontaneous adaptability, easy spread capacity, high reproductive potential (approx. 600 eggs in lifetime), and massive biotic strength (several generations of progeny in a year) make a potential risk of its introduction in a new area. The EPPO (The European and Mediterranean Plant Protection Organization) countries imposed this fly as of quarantine significance and classified it under the A1 list of pests (EPPO/CABI, 1997).

Adult female flies cause direct harm by laying eggs 
under the peel of the fruits and vegetables where the eggs hatch into larvae that feed on the decaying flesh of the crop. The infested fruits and vegetables rapidly become inedible or drop to the ground (Ekesi, 2011). Eventually the growers are unable to sell their products. Thus, suppression or eradication of these fruit fly pests has been the ultimate destination of control programs (Vargas, 2010; Estes, 2012). Various types of methods are incorporated with these programs such as chemical control (i.e., cover and bait sprays) based on conventional methods (organophosphates and pyrethroids), plant-borne insecticides (Danne, 2010; Canale, 2013), biotechnical tools (sterile insect technique and male annihilation technique) (Vargas, 2010; Lauzon, 2012; Benelli, 2014) as well as biological control (Canale, 2012; Sivinski, 2012; Vargas, 2012). During the last decade development of new procedures and methods for the biological control of this pest has gained considerable interest espcially in the use of their natural enemies, mass trapping systems and sterile insect technique (SIT). SIT is an environment friendly insect control method which involves mass rearing and sterilization by radiation. In field application sterile males mate with wild females resulting in no offspring and finally reducing the pest population. The International Plant Protection Convention categorizes sterile insects as beneficial organisms. The SIT involves the introduction of non-native biological control agents. According to them, sterile insects are not selfreplicating and therefore cannot become established in the environment; breaking the pest's reproductive cycle, thus called autocidal control; it is species-specific so that do not harm or affect other organisms in the environment. The SIT does not introduce non-native species into an ecosystem. Integrated with other control methods, the SIT has been successful in controlling a number of high-profile insect pests, including fruit flies, tsetse fly, screwworm, moths, and mosquitoes. In several countries where the technology has been applied, benefits include: a significant reduction in crop and livestock production damages; safety of the horticultural and livestock industries through prevention of pest introductions; ensuring access for commodity exports to high value markets without quarantine constraints; producing jobs; significant reduction in production and human health costs; and environmental security through a reduced use of insecticides (Tephritid fruit flies: https:// www.iaea.org/topics/sterile-insect-technique/tephritidfruit-flies). The development of SIT largely depends on the understanding of the genetics and cytogenetics of the target species which is an integral part of Integrated Pest Management (IPM). In recent years, IPM has been proved as a fruitful method for managing pestiferous fruit flies in an endeavor to sustainable fruit production (Vargas, 2008).
Dipteran polytene chromosomes are essential tools for studying chromosome structure and function, temporal gene activities and genomic organization (Zhimulev et al., 2004). The static banding pattern of polytene chromosomes often used to evaluate the phylogenetic relationships among closely related species or to differentiate members of a species complex (Garcia-Martine et al., 2009). It also provides a basic understanding of the construction of detailed physical genetic maps through the precise localization of genes or any isolated nucleic acid sequence by in situ hybridization (Pardue and Gall, 1975). The banding and inter banding patterns of each polytene chromosome are always species specific (Sumner, 2003) and are very important for the analysis of numerous aspects of the chromosomes itself and of the genome as a whole (Zhimulev, 2001). The main application of polytene chromosomes is in locating genes and identifying the structural map of the chromosome of the species (Gardner, 1975).

Genetics and cytogenetics of insect pests provide a fundamental knowledge for understanding the biology of this species and for the implementation of modern control techniques. Study on polytene chromosomes provide elaborate knowledge on the structure of the chromosomal rearrangement and their identification in the polytene genome. Present study aims to identify different polytene chromosome arms of Bactrocera zonata based on their characteristic tips and other distinguishable landmarks. The information can facilitate to separate the individual chromosome arm as an entity which will be needed for the construction of polytene chromosome map of this important pest species.

\section{Fly stock}

Laboratory colony of Bactrocera zonata was maintained in the Fruit Fly Laboratory, Radiation Entomology and Acarology Division, Institute of Food and Radiation Biology, Atomic Energy Research Establishment, Savar, Dhaka. Adults were fed on a mixture (1:3) of yeast:sugar. Larvae were reared on banana. Laboratory conditions were maintained at $25 \pm 2{ }^{\circ} \mathrm{C}$ with $70 \pm 5 \%$ Relative Humidity (RH) and $14 \mathrm{~h}$ light and $10 \mathrm{~h}$ dark cycle.

\section{Polytene chromosome preparations}

Polytene chromosome preparations were made from healthy third instar larvae (6-7 days old) of Bactrocera zonata according to the method of Zacharopoulou et al. (2011a, b). Salivary glands were dissected in $45 \%$ acetic acid and then fixed in $3 \mathrm{~N} \mathrm{HCL}$ for $2 \mathrm{~min}$. After fixing, tissue was transferred to $3: 2: 1$ solution of acetic acid: distilled water: lactic acid for 4-5 min and finally stained with lacto-acetic orcein for about 10-15 min. After staining, the slides were examined using Olympus phase contrast microscope (CX41) and well- 
distributed polytene chromosome nuclei were photographed. Polytene chromosomes with clear banding patterns were studied for identifying their tips.

Identification and numbering of the polytene chromosomes of Bactrocera zonata were done according to the methods followed for other tephritid species, B. oleae, B. tryoni, B. cucurbitae, B. papayae, B. carambolae and Ceratitis capitata, (Zacharopoulou, 1987, 1990; Zambetaki et al., 1995; Zhao et al., 1998; Shahjahan and Yesmin, 2002; Zacharopoulou et al., 2011, Yesmin and Clyde, 2012a-d). The identifying tips of each chromosome arm are detected by their specific feature. The length of two arms of each chromosome is unequal due to the position of centromere. In each chromosome, longer arm was mentioned as left arm (L) and the shorter as right arm (R).

Study on B. zonata polytene chromosomes showed that polytene nuclei consist of five long chromosomes holding ten polytene arms. Photographs of the polytene nucleus are given in Figures 1-10. A brief description associates with the characteristics landmarks of each polytene chromosome is presented here.

\section{Chromosome 2}

Left arm (2L) of this chromosome tip slightly swollen with one dark band and close two thin bands are the identifying landmark of this arm. The rounded tip with one thick band and one dark band is the characteristic mark of the right arm (2R). Several weak points make it difficult to analyze the banding pattern along the entire right arm. A bundle of dark band and a puff with one dark band in the middle of the puff near the $2 \mathrm{R}$ tip is the determine mark of this arm (Fig.1 and 2).

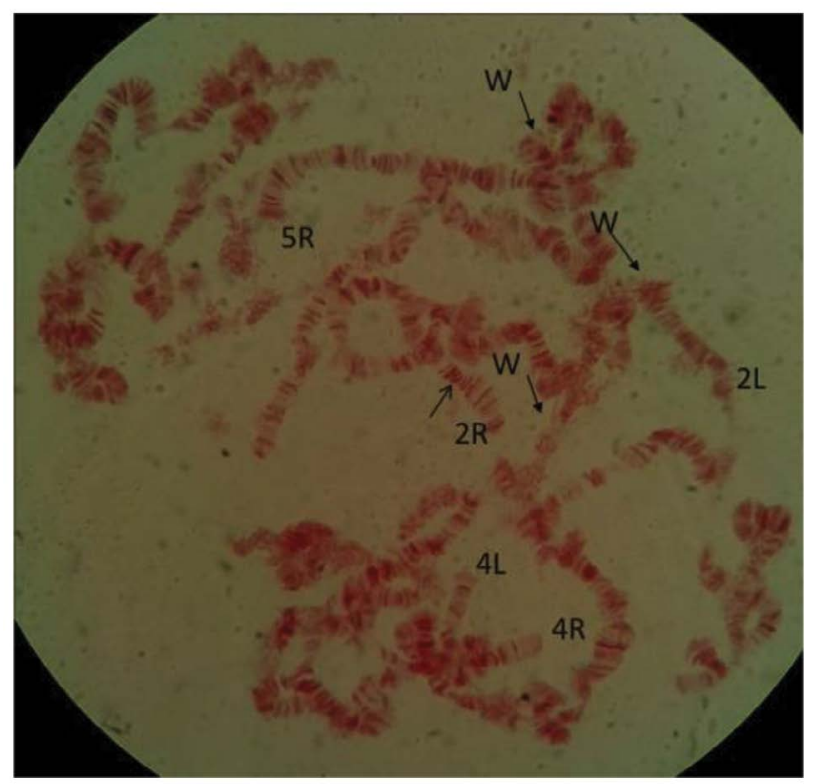

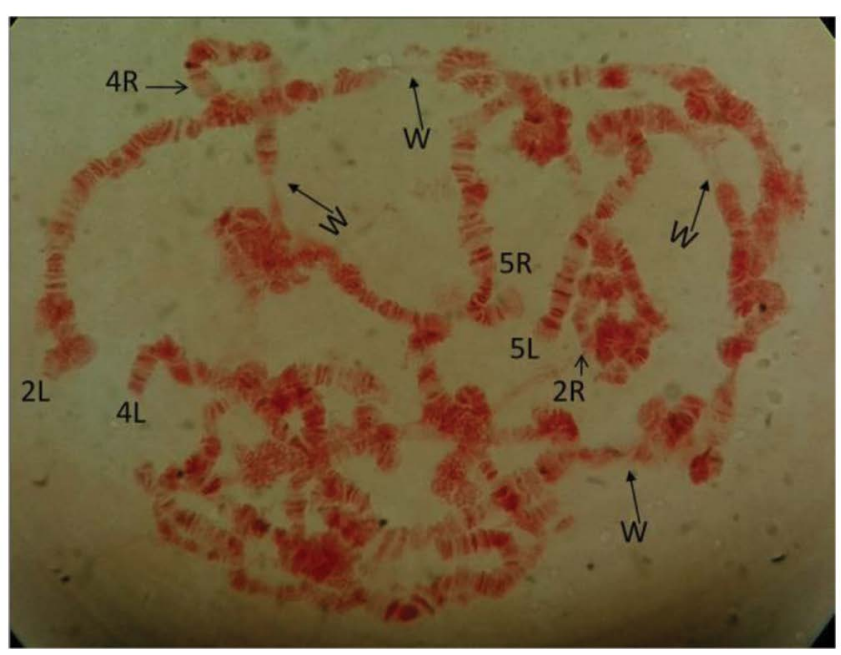

Fig. 2. Polytene nucleus of Bactrocera zonata showing chromosome 2, 4, 5. L-Left arm; R- Right arm; WWeak points.

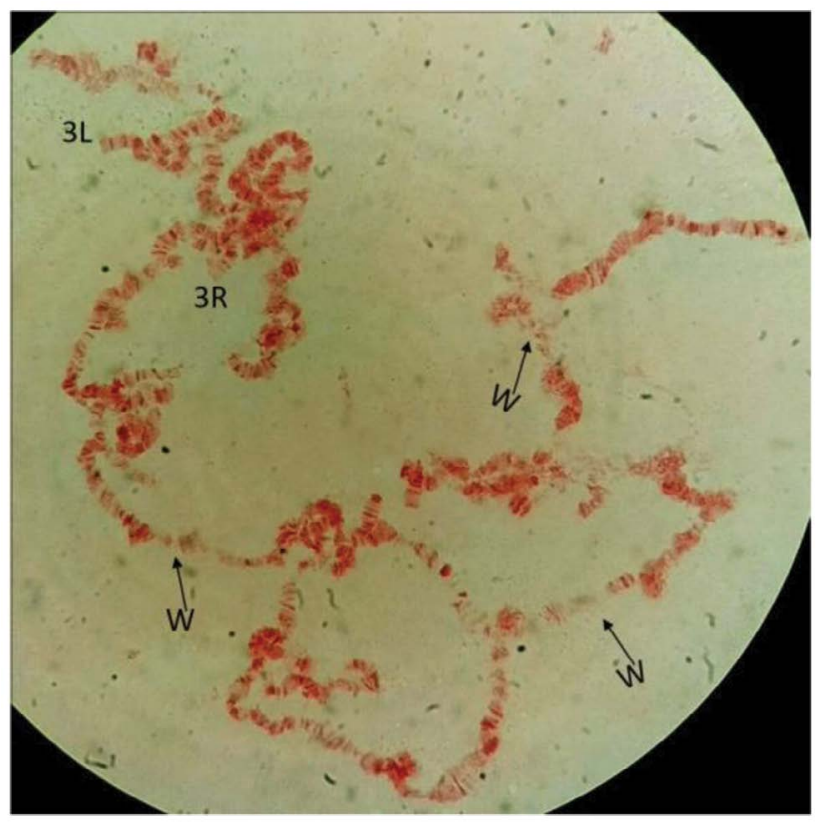

Fig. 3. Polytene nucleus of Bactrocera zonata showing chromosome 3. L-Left arm; R- Right arm; W- Weak points.

\section{Chromosome 3}

Both tips of this chromosome are identifiable by its convex shape. The $3 \mathrm{R}$ tip is readily recognized by a slight high point (dissimilarities form 5R) in the middle with some dotted band and a dark band followed by the expanded region. It is found in every polytene nucleus. The left arm (3L) tip is comparatively difficult to find out. The curve tip with one thin band close to one dark band is the identifying mark of this arm (Fig. 3, 5-9). 


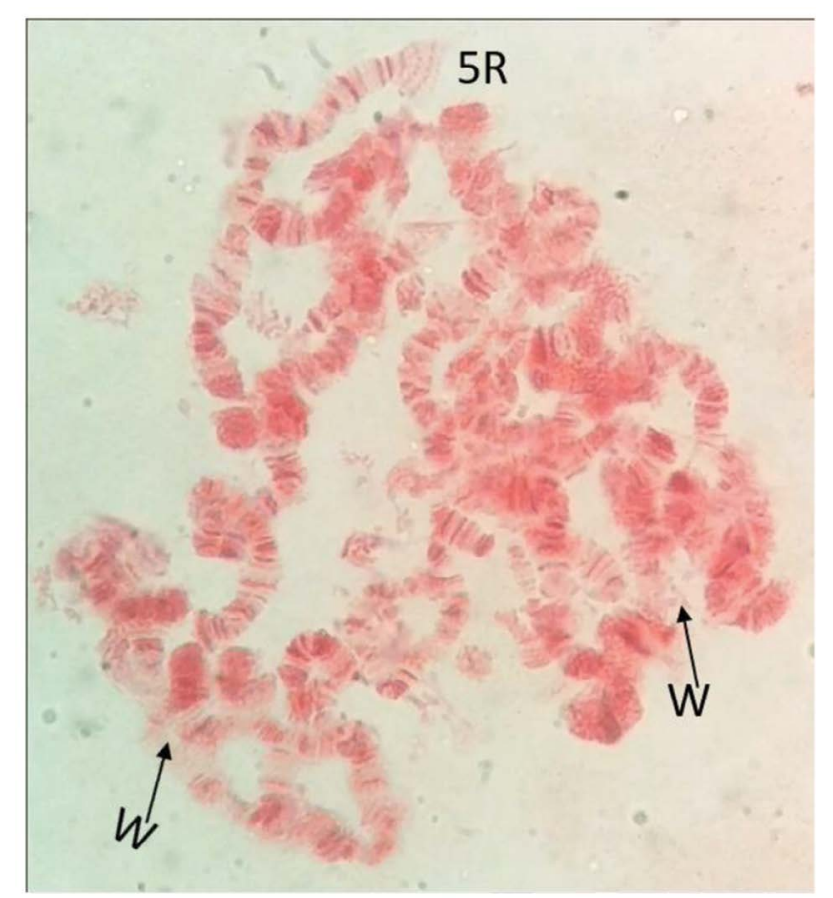

Fig. 4. Polytene nucleus of Bactrocera zonata showing chromosome arm 5R. R- Right arm; W- Weak points.

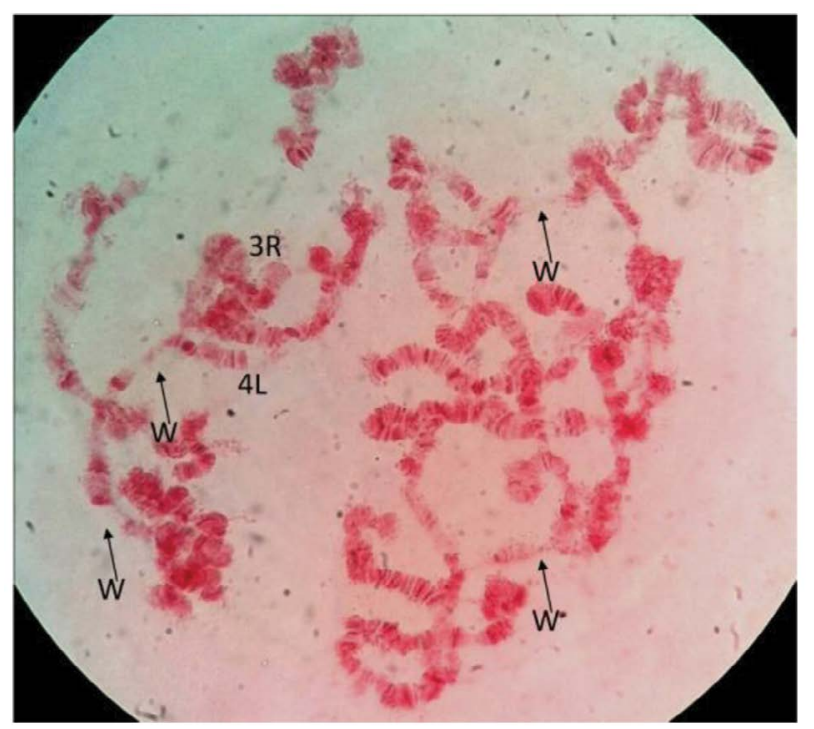

Fig. 5. Polytene nucleus of Bactrocera zonata showing chromosome 3, 4. L-Left arm; W- Weak points.

\section{Chromosome 4}

This chromosome is spontaneously visible in every polytene nucleus. It is comparatively easy to identify by its square shaped tip of both (right and left) arms. 4R tip end with a dark band with two close thick bands is the characteristic mark of this arm. The 4L tip composed of several thin bands with one dark band. A weak point near the tip is the identifying landmark of this arm (Fig. 1, 2, 5, 7-9).

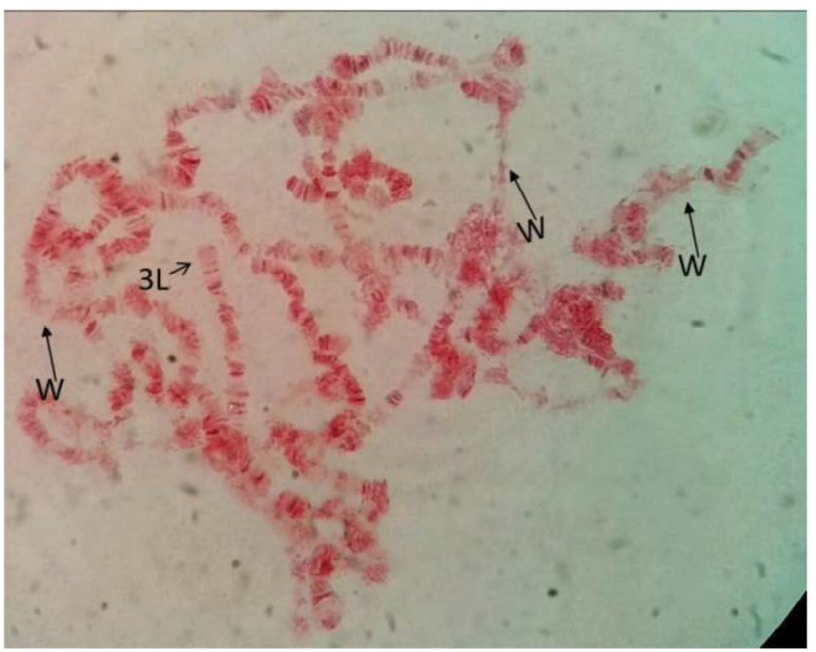

Fig. 6. Polytene nucleus of Bactrocera zonata showing chromosome arm 3L. L-Left arm; R- Right arm; WWeak points.

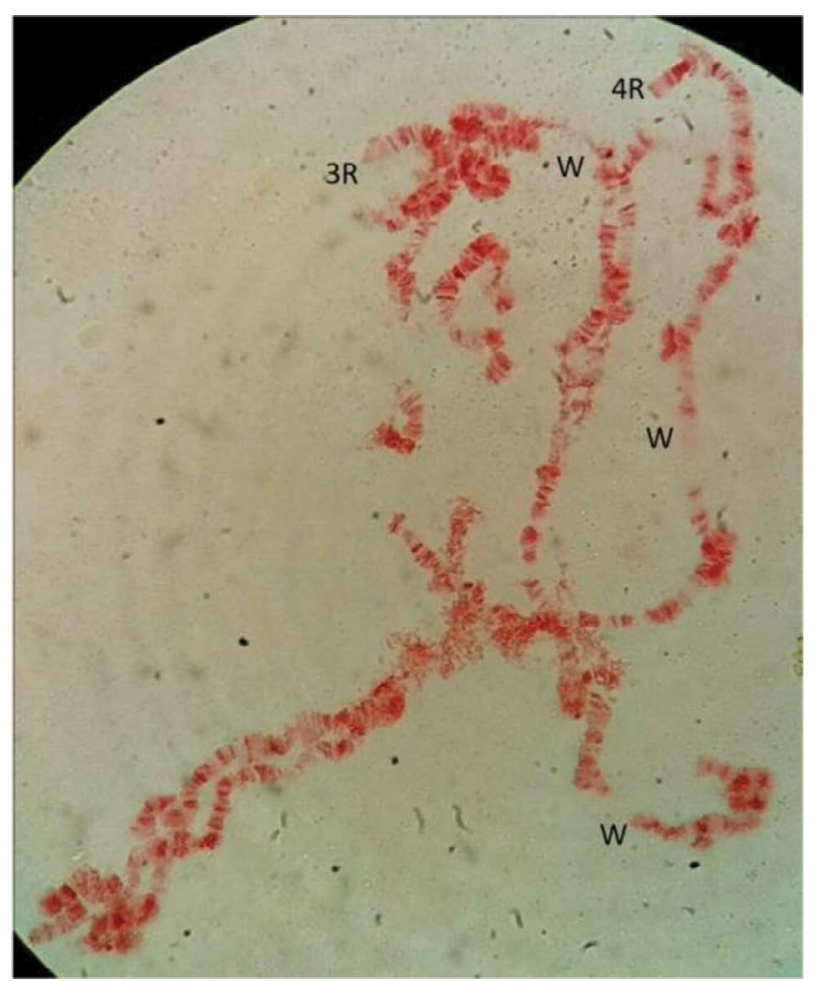

Fig. 7. Polytene nucleus of Bactrocera zonata showing chromosome 3, 4. L-Left arm;R- Right arm; W- Weak points.

\section{Chromosome 5}

The whole chromosome contains a well visible banding pattern than the other polytene chromosomes in nucleus of B. zonata. This chromosome easily locates in every polytene nucleus. Right arm tip end with three dark dotted band and fan shaped structure. One dark band at the expanded end close to two dark bands are the identifying landmark of the right arm 
(5R) tip, more prominent than the left arm (5L) tip. Two puffs and a constriction is the characteristic landmark of right arm. Left arm tip is slightly expanded composed of one dark band close to two thick bands (Fig. 1, 2, 4, 8).

\section{Chromosome 6}

This chromosome appears as smaller and not very clearly visible in polytene nucleus. Right arm (6R) tip is rounded composed of several dark bands and a puff near the tip with one thin band in the middle. The swollen tip of left

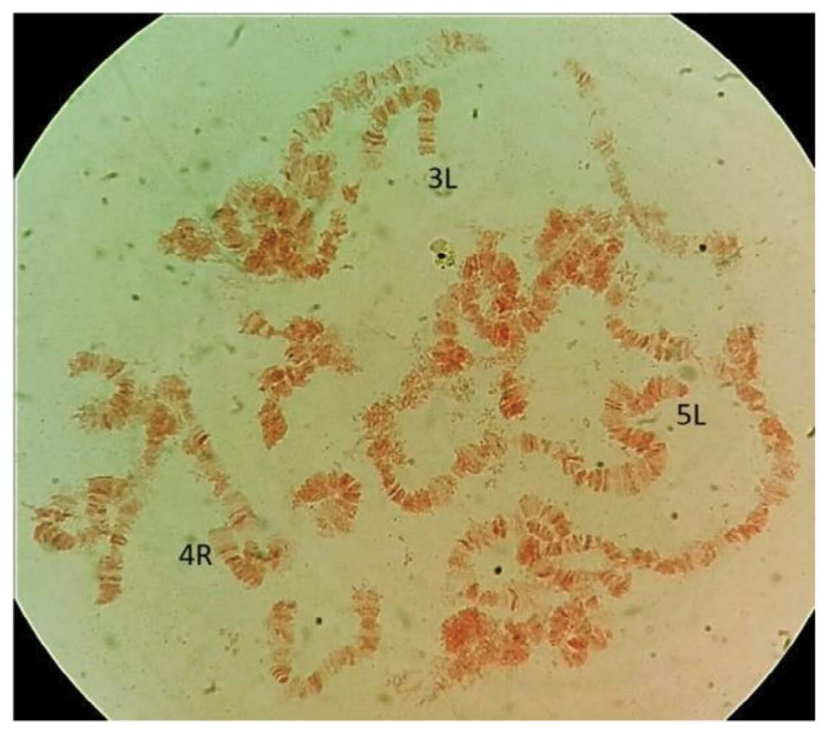

Fig. 8. Polytene nucleus of $B$. zonata showing chromosome 3, 4, 5 . L-Left arm; R- Right arm.

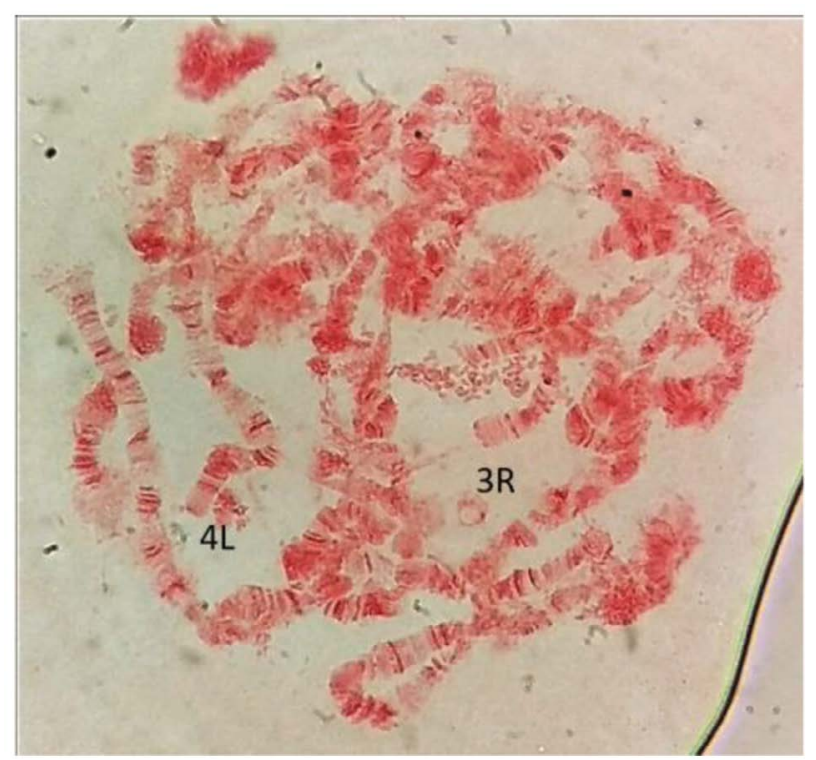

Fig. 9. Polytene nucleus of $\boldsymbol{B}$. zonata showing chromosome 3,4. L-Left arm; R- Right arm.

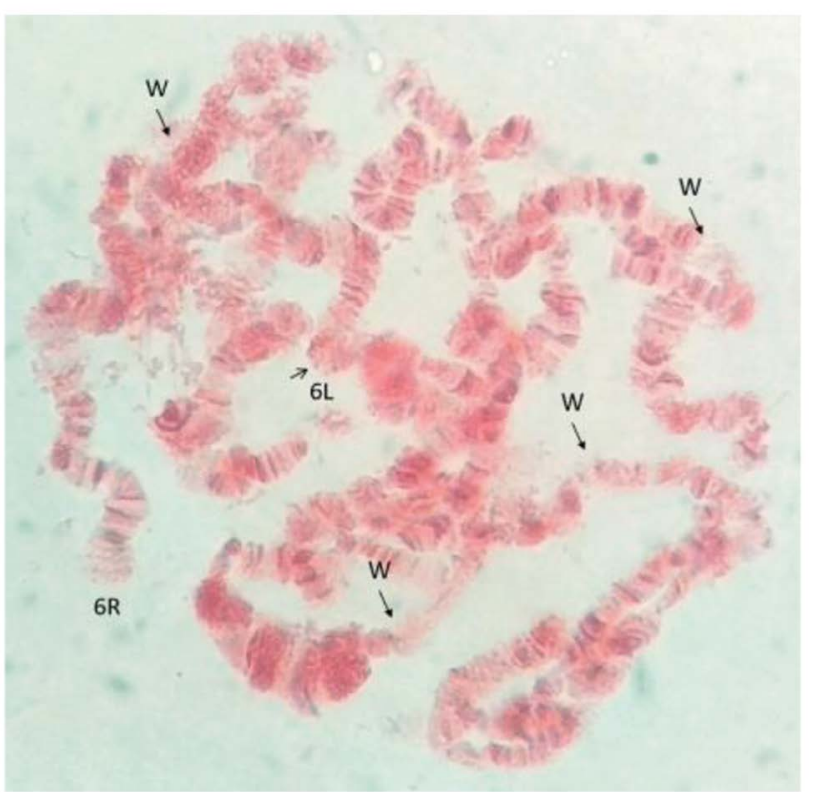

Fig. 10. Polytene nucleus of $\boldsymbol{B}$. zonata showing chromosome6. L-Left arm; R- Right arm; W- Weak points.

arm (6L) with thin band is the identifying mark of this tip (Fig. 10).

At present, polytene chromosomes of several fruit fly species of the family Tephritidae have been reported. Almost all of them reported five banded polytene chromosomes i.e., 10 polytene arms in the salivary gland polytenenuclei. Present findings are consistent with those report as for the med fly, Ceratitis capitata (Zacharopoulou 1987, 90), the olive fruit fly, Bactrocera oleae (Zambetaki et al., 1995), the Queensland fruit fly, B. tryoni (Zhao et al., 1998), the Melon fly, B. cucurbitae (Shahjahan and Yesmin, 2002; Zacharopoulou et al., 2011a), the Oriental fruit fly, B. dorsalis (Zacharopoulou et al., 2011b), the Asian papaya fruit fly, B. papayae (Yesmin and Clyde, 2012a,b) (at present this fly is known as $B$. dorsalis, Schutze et al., 2014 ) and the Carambola fruit fly, B. carambolae (Yesmin and Clyde, 2012c;d). Our results are also similar with other tephritid genera Anastrepha, Rhagoletis, Dacus spp. etc. (Schutze et al., 2015).

Polytene chromosomes served as an important element in genetic and cytogenetic study since their discovery in larval tissues of Drosophila and other Diptera (Painter, 1933; Ashburner, 1992). Polytene chromosome analysis of Ceratitis capitata, Lucilia cuprina, Dacus oleae and Bactrocera tryoni revealed that salivary gland chromosomes were very hard to spread because of comprehensive ectopic pairing (Zacharopoulou, 1987; 1990, Zambetaki et al., 1995). Generally, chromosomes were broken during slide preparation and very limited number of 
nucleus was found clear for analysis of their banding pattern as well as identifying tips. Such difficulties were also observed and reported by the authors in case of the above mentioned fruit fly genera. For B. zonata, we also faced this type of complications and the chromosomes were found by a large number of weak points, i.e., in this points chromosomes are usually broken here.

Salivary gland poytene chromosomes of the peach fruit fly, B. zonata were studied in order to identify their tips for the 10 polytene arms. The tips of every chromosome need to be identified because without tips one individual chromosome could not be separated for constructing the polytene chromosome map. The development of polytene chromosome map of the target pest is a fundamental need to make a Genetic Sexing Strain (GSS) which is a key component for the Sterile Insect Technique (SIT) application in an AW-IPM programme. SIT is a species specific method of birth control applied to target insect pest populations. Here, sterile male flies are released in the field to suppress or eradicate the target pest, thus sterile flies serve as biological control agent. This study is part of a research grant scheme of The World Academy of Sciences (TWAS) under Individual Category. Precise localization of each chromosome in polytene nuclei of B. zonata, their centro mere position, distinguished landmarks, puffs as well as corresponding mitotic metaphase chromosome structure are is in progress in the fruit fly laboratory of the Institute of Food and Radiation Biology (IFRB) under supervision of first author.

\section{ACKNOWLEDGEMENTS}

This research was undertaken by a research grant of The World Academy of Sciences (TWAS Ref. 16-062RG/BIO/ As_IFR3240293325). MNU was supported by a fellowship from the National University of Bangladesh.

\section{REFERENCES}

Ashburner M. 1992. Mapping insect genomes, pp. 51-75. In: Crampton IM, Eggleston P. (Eds.). Insect Molecular Science. Academic press Ltd, London, UK.

Benelli G, Daane KM, Canale A, Niu CY, Messing RH, Vargas RI. 2014. Sexual communication and related behaviours in Tephritidae-Current knowledge and potential applications for Integrated Pest Management. J Pest Sci. 87: 385-405. https://doi.org/10.1007/s10340-014-0577-3

Canale A, Benelli G, Conti B, Lenzi G, Flamini G, Francini A, Cioni PL. 2013. Ingestion toxicity of three Lamiaceae essential oils incorporated in protein baits against the olive fruit fly, Bactrocera oleae (Rossi) (Diptera: Tephritidae).
Nat Prod Res. 27: 2091-2099.https://doi.org/10.1080/147 86419.2013.784871 PMid:23594314

Canale A, Benelli G. 2012. Impact of mass-rearing on the host-seeking behaviour and parasitism by the fruit fly parasitoid Psyttalia concolor (Szepligeti) (Hymenoptera: Braconidae). J Pest Sci. 85: 65-74. https://doi.org/10.1007/s10340-011-0382-1

Clarke AR, Powell KS, Weldon CW, Taylor PW. 2011. The ecology of Bactrocera tryoni (Diptera: Tephritidae): What do we know to assist pest management? Annu Appl Biol. 158: 26-54. https://doi.org/10.1111/j.17447348.2010.00448.x

Daane KM, Johnson MW. 2010. Olive fruit fly: Managing and ancient pest in modern times. Annu Rev Entomol. 55: 151169.https://doi.org/10.1146/annurev.ento.54.110807.090553 PMid:19961328

Drew RAI, Hancock DL. 2000. Phylogeny of the tribe Dacini (Dacinae) based on morphological, distributional, and biological data, pp. 491-504. In: Aluja M and Norrbom AL (Eds.). Fruit Flies (Tephritidae): Phylogeny and Evolution of Behavior. CRC Press, Boca Raton, FL, USA.

Ekesi S, Mohamed SA. 2011. Mass rearing and quality control parameters for tephritid fruit flies of economic importance in Africa, pp. 387-410. In: Akyar I. (Eds.). Wide Spectra of Quality Control. In: Tech, Rijeka, Croatia. https://doi.org/10.5772/21330

EPPO/CABI. 1997. Bactrocera dorsalis. Bactrocera zonata. Quarantine Pests for Europe, Second Edition, CAB International, Wallingfrod, UK.

Estes AM, Nestel D, Belcari A, Jessup A, Rempoulakis P, Economopoulos AP. 2012. A basis for the renewal of sterile insect technique for the olive fly, Bactrocera oleae (Rossi). J Appl Entomol. 136: 1-16.https://doi.org/10.1111/j.14390418.2011.01620.x

FAO/IAEA website. Tephritid fruit flies: https://www.iaea. org/topics/sterile-insect-technique. 14.11.2018.

Garcia-Martinez V, Hernandez-Ortiz E, Zepeta-Cisneros CS, Robinson AS, Zacharopoulou A, Franz G. 2009. Mitotic and polytene chromosome analysis in the Mexican fruit fly, Anastrepha ludens (Loew) (Diptera: Tephritidae). Genome, 52: 20-30. https://doi.org/10.1139/G08-099 PMid:19132068

Gardner EJ, Snustad DP. 1975. Principles of Genetics. 5th Edn. John Wiley \& Sons, Inc. 
Hendrichs J, Robinson AS, Cayol JP, Enkerlin W. 2002. Medfly area wide sterile insect technique porgrammes for prevention, suppression or eradication: the importance of mating behavior studies. Fla Entomol. 85: 1-13. https:// doi.org/10.1653/0015-4040(2002)085[0001:MASITP]2.0 .CO;2

Kapoor VC. 1993. Indian Fruit Flies (Insecta: Diptera: Tephritidae). New Delhi, India; Oxford, UK, IBH publishing Company, New Delhi, India.

Lauzon CR, Potter SE. 2012. Description of the irradiated and non irradiated midgut of Ceratitis capitata (Wiedemann) (Diptera: Tephritidae) and Anastrepha ludens (Loew) (Diptera: Tephritidae) used for sterile insect technique. J Pest Sci. 85: 217-226. https://doi.org/10.1007/s10340011-0410-1

Leblanc L. Hossain MA, Khan SA, San Jose M, Rubinoff D. 2013. A preliminary survey of the fruit flies (Diptera: Tephritidae: Dacinae) of Bangladesh. Proc Hawaiian Entomol Soc. 45: 51-58

Liu X, Jin Y, Ye H. 2013. Recent spread and climatic ecological niche of the invasive guava fruit fly, Bactrocera correcta, in mainland China. J Pest Sci. 86: 449-458. https://doi. org/10.1007/s10340-013-0488-8

Norrbom AL. 2010. Tephritidae (Fruit Flies, Moscas de Frutas), pp. 909-954. In: Brown BV, Borkent A, Cumming JM, Wood DM, Woodley NE, Zumbado MA. (Eds.). Manual of Central American Diptera. NRC-CNRC Research Press, Ottawa, Canada.

Painter TS. 1933. A new method for the study of chromosome rearrangements and the plotting of chromosome maps. Science 78: 585-586. https://doi.org/10.1126/ science.78.2034.585 PMid:17801695

PardueML, GallJG. 1975.NucleicacidhybridizationtotheDNA of cytological preparations. Methods Cell Biol. 10: 1-16. https://doi.org/10.1016/S0091-679X(08)60727-X

Qureshi ZA, Ashraf M, Bughio AR, Siddiqui QH. 1975. Population fluctuation and dispersal studies of the fruit fly, Dacus zonatus Saunders, pp. 201-206. International Atomic Energy Agency; Food and Agriculture Organization: Sterility principle for insect control. 1974. Proceedings of the symposium on the sterility principle for insect control jointly organized by the IAEA and the FAO of the United Nations and held in Innsbruck, 22-26 July 1974. International Atomic Energy Agency. Vienna Austria.
Qureshi ZA, Hussain T, Siddique QH. 1991. Relative preference of mango varieties by Dacus zonatus (Saunders) and D. dorsalis (Hendel). Pakistan J Zool. 23: $85-87$.

Schutze M, Aketarawong N, Amornsak W, Armstrong KF, Augustinos AA, Barr N, Bo W, Bourtzis K, Boykin LM, Caceres C, Cameron SL, Chapman TA, Chinvinijkul S, Chomic A, de Meyer M, Drosopoulou E, Englenou A, Ekesi S, Gariou-Papalexiou A, Geib SM, Hailstones D, Hasanuzzaman M, Haymer D, Hee, AKW, Hendrichs J, Jessup A, Ji Q, Khamis FM, Krosch MN, Leblanc L, Mahmood K, Malacrida AR, Mavragani-Tsipidou P, Mwatawala M, Nishida R, Ono H, Reyes J, Rubinoff D, Sanjose M, Shelly TE, Srikachar S, Tan KH, Thanaphum S, Haq I, Vijaysegaran S, Wee SL, Yesmin F, Zacharopoulou A, Clarke AR. 2015. Synonymization of key pest species within the Bactrocera dorsalis species complex (Diptera: Tephritidae): taxonomic changes based on a review of 20 years of integrative morphological, molecular, cytogenetic, behavioural and chemoecological data. Sys Entomol. 40: 456-471. https://doi.org/10.1111/syen.12113

Shahjahan RM, Yesmin F. 2002. Polytene chromosome maps of the melon fly, Bactrocera cucurbitae (Coq.) (Diptera: Tephritidae). Genome 15: 1167-1174. https://doi. org/10.1139/g02-081

Sivinski J, Aluja M. 2012. The roles of parasitoid foraging for hosts, food and mates in the augmentative control of Tephirtidae. Insects 3: 668-691. https://doi.org/10.3390/ insects3030668 PMid:26466622 PMCid:PMC4553583

Sumner AT. 2003. Chromosomes: organization and function. Blackwell Publishing. 287 pp.

Uchoa MA, Nicacio JN. 2010. New records of Neotropical fruit flies (Tephritidae), lance flies (Lonchaediaed) (Diptera: Tephritoidea), and their host plants in the South pantanal and adjacent areas, Brazil. Ann Entomol Soc America 103: 723-733. https://doi.org/10.1603/ AN09179

Vargas RI, Leblanc L, Harris EJ, Manoukis NC. 2012. Regional suppression of Bactrocera fruit flies (Diptera: Tephritidae) in the Pacific through biological control and prospects for future introductions into other areas of the world. Insects 3: 727-742. https://doi.org/10.3390/insects3030727

Vargas RI, Mau RFL, Jang EB, Faust RM, Wong L. 2008. The Hawaii fruit fly area wide pest management 
programme, pp. 300-325. In: Koul O, Cuperus G. (Eds.). Area wide Pest Management: Theory and Implementation. CABI Books, London, UK. https://doi. org/10.1079/9781845933722.0300

Vargas RI, Shelly TE, Leblanc L, Pinero JC. 2010. Recent advances in methyl eugenol and cue lure technologies for fruit fly detection, monitoring and control in Hawaii, pp. 575-596. In: Liwack G. (Eds.). Vitamins and Hormones. Elsevier Inc, Academic press, Burlington, UK.

Yesmin F, Clyde MM. 2102a. Identification and characterization of polytene chromosomes of Bactrocera papaya (Diptera: Tephritidae). Malaysian Appl Biol. 41: 11-18.

Yesmin F, Clyde MM. 2012b. Salivary gland polytene chromosome maps of the Asian papaya fruit fly, Bactrocera papaya (Diptera: Tephritidae). Acad J Entomol. 5: 126-132.

Yesmin F, Clyde MM. 2012c. The chromosomes of the Carambola fruit fly, Bactrocera carambolae (Diptera: Tephritidae): Metaphase karyotype and polytene genome. GSTF J Biosci. 1: 10-15.

Yesmin F, Clyde MM. 2012d. Polytene Chromosome Analysis of Bactrocera carambolae (Diptera: Tephritidae). Curr Res J Biol Sci. 4: 725-730.

Zacharopoulou A. 1987. Cytogenetic analysis of mitotic and salivary gland chromosomes in the Medfly Ceratitis capitata. Genome 29: 67-71. https://doi.org/10.1139/ g87-011

Zacharopoulou A. 1990. Polytene chromosome maps in the medfly Ceratitis capitata. Genome 33: 184-197. https:// doi.org/10.1139/g90-030
Zacharopoulou A, Sayed WAA, Augustinos AA, Yesmin F, Robinson AS, Franz G. 2011a. Analysis of mitotic and polytene chromosomes and photographic polytene chromosome map in Bactrocera cucurbitae (Diptera: Tephritidae). Ann Entomol Soc Am. 104: 306-318. https://doi.org/10.1603/AN10113

Zacharopoulou, A., A.A. Augustinos, W.A.A. Sayed, A.S. Robinson and G. Franz, 2011b. Mitotic and polytene chromosomes analysis of the oriental fruit fly, Bactrocera dorsalis (Hendel) (Diptera:Tephritidae). Genetica 139: 79-90. $\quad$ https://doi.org/10.1007/s10709-010-9495-3 PMid:20844937

Zambetaki A, Kleanthous K, Mavragani-Tsipudou P. 1995. Cytogenetic analysis of malpighin tubule and salivary gland polytene chromosomes of Bactrocera oleae (Dacusoleae) Diptera: Tephritidae. Genome 38: 1070-1081.

Zhao JT, Frommer M, Sved JA, Zacharopoulou A. 1998. Mitotic and polytene chromosome analyses in the Queensland fruit fly, Bactrocera tryoni (Diptera: Tephritidae). Genome 41: 510-526. https://doi. org/10.1139/g98-053

Zhimulev IF, Belayaeva ES, Semeshin VF, Koryakov DE, Demakov SA, Demakova OV, Pokholkova GV, Andreyeva EN. 2004. Polytene chromosomes: 70 years of genetic research. Int Rev Cytol. 241: 203-275. https:// doi.org/10.1016/S0074-7696(04)41004-3

Zhimulev IF. 2001. Polytene chromosomes in Encyclopedia of life sciences. John Wiley \& Sons. PMCid:PMC14628 